\title{
LA INSTRUMENTALIZACION DE LA MUJER POR LA MEDICINA SOCIAL EN ESPAÑA A PRINCIPIO DE SIGLO: SU PAPEL EN LA LUCHA ANTIALCOHOLICA
}

\section{Ricardo Campos Marín}

A principios de este siglo el alcoholismo fue objeto de interés científico en los círculos académicos españoles. Su estudio, como en toda Europa, se desarrolló desde una perspectiva multidisciplinar (antropología, medicina, derecho, etc.), en tres direcciones: desentrañar su etiología, definir la patología y establecer las bases para erradicarlo de la sociedad y crear los mecanismos de defensa social necesarios frente a su amenaza. El aumento de la criminalidad y la preocupación por la degeneración de la raza, fueron los dos pilares en los que la medicina, y por extensión las otras disciplinas, se basaron para demostrar los peligros que corría la sociedad entera y constituyeron la piedra de toque de la propaganda antialcohólica. Ante este problema y de la mano del reformismo social, se ensayó la elaboración de un programa de actuación contra el alcoholismo, encaminado a controlar y reprimir al contingente de población que ingería en exceso bebidas etílicas (1).

En líneas generales se relacionó el alcoholismo con la clase trabajadora, haciéndose común la figura del obrero borracho, individuo peligroso que cuestionaba la estabilidad de la sociedad burguesa con sus excesos e inmoralidad (2).

Uno de los objetivos primordiales de esta lucha fue la familia. La 
necesidad de crear familias estables, en especial en el ámbito obrero, que recogiesen e interiorizasen las virtudes y moral burguesas para generar individuos sanos, obedientes y por tanto no peligrosos, dio a la mujer, concebida como madre y esposa, un papel fundamental en este programa. Su misión era transmitir los principios básicos de higiene que la medicina consideraba oportunos para trasladar al núcleo familiar el modelo de valores que propugnaba la burguesía.

En el presente trabajo se esbozan, a través del estudio de cinco Premios Roel de la Sociedad Española de Higiene dedicados a diversos aspectos de la salud y educación de la mujer, y de un conjunto de trabajos sobre el alcoholismo en el período 1900-1923, algunos problemas que con la instrumentalización del sexo femenino para controlar los hogares, se le plantearon a la medicina social.

\section{Los peligros del alcohol}

Desde que en 1857 Morel apreció que el alcoholismo era una de las causas fundamentales de la degeneración de la especie, se abrió un hilo conductor en la explicación de la intoxicación etílica que, con variantes, constituyó el recurso interpretativo de la psiquiatría y de todas aquellas disciplinas que se acercaron a la cuestión. En España la vulgarización de los conceptos vertidos por la psiquiatría positivista francesa, conllevaron la transformación del degeneracionismo en un sistema explicativo simplista y mecanicista que adquirió el rango de cajón de sastre (3).

La herencia aparecía como el principal factor etiológico del alcoholismo y de la degeneración. Muñoz Ruiz de Pasanis es claro al respecto al señalar que:

«La herencia alcohólica es el punto más importante de todo lo relativo al alcoholismo, porque afecta no sólo al individuo, sino a la familia y a la raza» (4).

El heredo-alcoholismo, además de constituir la causa principal de la embriaguez, llevaba consigo la predisposición por parte de los herederos de contraer toda una serie de enfermedades que portaban la semilla degenerativa. Según esto y siguiendo las palabras de Ferrer y García Tejero, que no son sino una repetición mecánica de lo dicho por la psiquiatría francesa, nos encontramos con que 
«- El alcoholismo socava todos los fundamentos de la civilización, llevando a los pueblos el raquitismo, la insensatez y el crimen.

- Alcanzando a los niños por herencia, el alcohol conduce un país a su perdición.

- Los excesos cometidos por los padres, recaen sobre los hijos: si estos sobreviven algunos meses, son atacados de idiotismo o epilepsia, o aún peor, un poco más tarde son arrebatados por meningitis, tuberculosis o consunción.

- Muchos de los hijos de padres alcohólicos son idiotas hidrocefálicos o neuróticos y mueren en edad temprana. Entre los supervivientes se observan a menudo la tuberculosis, la epilepsia, el histerismo y las enfermedades mentales.» (5).

Los fundamentos de la civilización (la moral y el orden burgués) corrían peligro por culpa de los abusos etílicos que contribuían a crear por vía hereditaria cuerpos predispuestos a todo tipo de enfermedades físicas y mentales. La tendencia al crimen, la locura y la muerte eran el final que esperaba al alcohólico y a su descendencia. El cuadro que se presentaba era pesimista, pues no se ofrecía ninguna solución y la familia afectada por el alcoholismo estaba condenada a desaparecer en la cuarta generación (6), lo que condujo a definir al alcohólico como enemigo de todo:

«El alcohólico es, en una palabra, y como hemos dicho en otro lugar, enemigo de sí mismo, de su familia y de su patria, y debe procurarse por todos los medios imaginables extirpar de raíz, si fuera posible, esa plaga, que al propio tiempo es una vergüenza de la humanidad» (7).

Sin embargo, el problema de las causas del alcoholismo no se circunscribió exclusivamente al terreno del determinismo hereditario, sino que los estudiosos del tema, centraron su atención en el medio social. Una vez establecido que el alcoholismo era una de las causas principales de la degeneración de la especie por vía hereditaria, los estudiosos del tema se preguntaron dónde residía la causa última de este azote, y centraron sus miradas en el medio social. La transformación de las condiciones sociales y económicas que consigo trajo la nueva sociedad capitalista, con la industrialización y la aparición del proletariado que vivía en condiciones infrahumanas, no pasó desapercibida a los médicos de la época. De hecho se estableció una identificación entre las enfermedades que afectaban a la sociedad en aquel momento y el medio 
obrero. El alcoholismo a estos efectos era un ejemplo perfecto. En cualquier caso no conviene exagerar la importancia que se le daba a las condiciones de vida del obrero como factor etiológico del alcoholismo, pues si bien la mayoría de los autores tomaban en cuenta la mala vivienda, el hacinamiento, las malas condiciones de trabajo, etc., consideraban que el obrero era en sí mismo vicioso e intemperante y que por tanto era el culpable de su miseria y desdichas (8). Esta posición, dominante en el panorama español, trasladaba el problema y su solución, al terreno de la moral, donde se habían de centrar los esfuerzos de los médicos, abogados, antropólogos y demás interesados por el alcoholismo, porque

"la mejora de las condiciones morales y de la instrucción antialcohólica de las masas trabajadoras que, sin la traba de esa mayor moralidad y de esa mejor educación, invertirán seguramente los mayores rendimientos que obtengan en engrosar las filas de la intemperancia, con perjuicio de los intereses de la familia y de la sociedad» (9).

Detrás de esta argumentación se encontraba la necesidad de controlar a amplias capas de la población consideradas peligrosas, especialmente al obrero que a través de organizaciones sindicales y políticas planteaba conflictos no deseados por la burguesía. De hecho, la imagen del obrero borracho creada por la burguesía es utilizada con intención política al relacionar algunos autores el paro y la subversión con el alcoholismo. La indisciplina y la vagancia son defectos del alcohólico que le conducen a la miseria, por lo que no se duda en afirmar que hay "motivos poderosos para creer que una parte de los "sin trabajo" no deban al progreso de la máquina, ni a la avaricia del burgués el carecer de ocupación» (10). Estos obreros alcoholizados, vagos y rencorosos, son los que toman en los mitines y huelgas las medidas más violentas, al percibir en el burgués su adversario y no «el que en sí llevan» (11). Estos razonamientos provocaron la propuesta de medidas antialcohólicas especiales para los obreros, encaminadas a su despolitización. Así el doctor Ubeda de Correal proponía la creación de círculos obreros en las fábricas en los que se encontrasen cómodos y practicasen actividades no perjudiciales para la salud, y en los que la política estuviese absolutamente prohibida (12). La sanción económica del obrero que bebía alcohol, bien despidiéndole, bien castigándole sin aumentarle el sueldo, era otro tipo de medida propuesta con la intención de reprimir y romper lazos de clase al intentar mostrar como ejem- 
plares a aquellos que no bebían (13). En definitiva, con éstas y otras medidas se intentaba moralizar al obrero, hacer de él un individuo respetuoso con la sociedad, apartarle de los senderos del vicio, darle un mínimo de calidad de vida a través de planes de mejora de la vivienda, de leyes encaminadas a la protección del trabajo. Educar voluntades, en expresión de Alvarez Uría, sin atacar los problemas más allá de la barrera del reformismo social (14).

La familia era el terreno abonado para que la medicina social intentase, en nombre de la salud y de la higiene, inculcar los valores que la sociedad burguesa defendía, y la mujer su correa de transmisión.

\section{La medicina social y la educación de la mujer}

A principios de siglo, en España el pensamiento predominante respecto al papel de la mujer era el clásico de madre y esposa. Si bien existían ciertas disidencias agrupadas en torno al krausismo, al anarquismo y al socialismo, se admitía en la sociedad la concepción burguesa de la mujer sin crítica (15). La medicina social no fue ajena a la tónica general del período. Los textos médicos que abordan el problema de la mujer como transmisora de los principios higiénicos al contexto familiar son elocuentes y destilan una escasez de originalidad que conduce al esquematismo y a la reproducción monótona de una serie de ideas, que sin embargo, y el ejemplo de la lucha contra el alcoholismo por parte de la medicina social es ilustrativo, poseen intenciones muy precisas de control.

En 1923 se concedió el Premio Roel de la Sociedad Española de Higiene a Emilia Pérez de Muñoz Iriarte, maestra normal superior, por su trabajo Escuelas del hogar. Cuál debe ser su organización y qué materias de Enseñanza deben comprender para la educación útil de jóvenes de clases modestas. La importancia de este trabajo radica en que constituye una declaración programática sobre la educación de la mujer. Dirigido a las hijas de clase media y obrera, su objetivo era educar mujeres para que desempeñasen el papel de perfectas amas de casa, creando las condiciones del hogar ideal, que era definido como

«aquel que produzca satisfacción en los sentidos, bienestar en el espíritu. Y saber que para llegar a estas condiciones tan esenciales para la vida no precisa ni lujo ni "confort"; bastan el orden, la limpieza y la exquisitez espiritual emanada de una educación adecuada ca- 
suística y personal, que inspire hasta los actos más elementales, cuya propia sencillez sea precisamente la mayor garantía de su éxito» (16).

Se pretendía así que el equilibrio en el hogar estaba al alcance de cualquier mujer, independientemente de la clase social a la que perteneciese, pues los problemas en el hogar del obrero no se planteaban exclusivamente como una cuestión de condiciones materiales de vida, sino como consecuencia de la carencia de valores morales. Estos debían introducirse a través de una adecuada educación de las mujeres en las ocupaciones propias de su sexo en «el seno de la familia e inculcarlas hábitos de trabajo, de orden y economía» (17), con el objetivo de proporcionar a las alumnas modestas los instrumentos «que les permitan sostener o mejorar su situación» (18). Se trataba de llevar a los hogares modestos la idea de que no era necesario transformar las condiciones socio-económicas del sistema para mejorar las mismas, sino que poniendo al alcance de las familias modestas, por medio de una educación precisa, los instrumentos necesarios, podían rentabilizar al máximo sus escasos recursos. En este sentido las enseñazas impartidas variarían según la clase social a que se dirigiesen, intentando aplicar un criterio positivo y práctico directamente enlazado con las «necesidades corrientes de la vida, dando la solución a los pequeños problemas domésticos de una medianía social modesta o humilde» (19).

La idea no era nueva ya que, veintidós años antes, el doctor Ubeda de Correal, en su estudio titulado El alcoholismo, apuntaba ya la necesidad de crear escuelas prácticas para las hijas de los obreros en las que se hiciese de estas «verdaderas y útiles compañeras, para el día de mañana, del obrero, conocedoras del arreglo de una casa modesta..., para ser en una palabra un ama de casa económica, ordenada y agradables cualidades en las que se cifra el secreto de la felicidad de un hogar, por humilde que sea» (20), insistiendo en la necesidad de que en estas escuelas se les ofreciera una educación específica que les mostrase «los inconvenientes que la embriaguez y el alcoholismo tienen para el individuo, la familia, la sociedad y la patria» (21). En el período de tiempo que media entre los dos textos, no parece que se hiciese gran cosa en la práctica, si creemos a Emilia Pérez, cuando afirma que el Estado sólo creó una Escuela del Hogar en 1912 en Madrid, dejando al margen ciudades de la importancia de Barcelona o Sevilla (22).

Aunque la mayoría de los textos consideran que la mujer reúne una serie de condiciones innatas para cumplir su misión educativa y moralizadora en el seno del hogar (cariño, encantos, capacidad de hablar al 
alma y de hacerse oír (23)) son concluyentes al resaltar la existencia de tendencias a desviarse de sus tareas, por un mal entendimiento de sus funciones, creando un hogar incómodo que justifica que los hijos y el esposo busquen fuera de él

"lo que necesitan y el hogar les niega; buscan aseo, alegre compensación a sus esfuerzos, alivio a sus pesares, calor a sus esperanzas, olvido a sus agravios... y se domicilian donde lo hallan, aunque sólo sea en apariencia. Por eso pasan las horas en el café o en la taberna, en el burdel o en el garito: allí al menos les brindan comodidades y distracciones» (24).

Por tanto se responsabiliza a la mujer del buen o mal funcionamiento de su hogar, al igual que se culpa al obrero de su situación. De esta manera la burguesía procuraba, sino eludir sus responsabilidades sociales, sí al menos relativizarlas planteando la cuestión en el terreno de la individualidad y del voluntarismo, ofreciendo los instrumentos necesarios - la educación-para llegar a buen puerto en sus objetivos de salvar la conflictividad social. Como alternativa a esa mujer incapaz, que conduce a los suyos a buscar el bienestar en el alcohol, se propone modelar un tipo de fémina que sea "activa sin ser esclava, económica sin ser tacaña, pulcra sin ser coqueta, ordenada sin ser meticulosa, risueña sin llegar a zalamera» (25), que alcance la consecución de un ambiente agradable en el hogar, diluyendo todo conato de enfrentamiento, y abriendo al varón la posibilidad de «vivir la verdadera vida, la vida de las emociones, la vida del ego consciente y libre», que definitivamente le alejará del alcohol (26).

La educación correcta de la mujer pasaba por la higiene. La mayoría de los autores consideraban que ésta jugaba un papel de primer orden en la formación femenina. En este sentido, Eduardo Buisan describía con precisión la relación entre la mujer y el papel de la higiene en su educación al afirmar:

"Conseguida una mujer buena y hermosa, hay que concederle la inteligencia, pues sin ella, no podríamos educarla según nuestro deseo. ¿Cómo es posible inculcarle, si su mentalidad es escasa, los preceptos higiénicos indispensables para la buena conservación de la salud de sus hijos, y qué consejos morales ha de dar a estos, si antes no ha comprendido bien la misión higiénica educadora que le está encomendada?» (27). 
La inteligencia de la mujer se consideraba un don, en tanto y cuanto estaba subordinada a la necesidad de la comprensión de las enseñanzas de la higiene. El sexo femenino constituía así un mero instrumento para hacer llegar a los hogares los principios higiénicos y morales, que aparentemente se disfrazaban con el velo del interés general, pero que tenían una evidente conexión con la ideología dominante. Además en este texto se plantea el mecanismo de funcionamiento del proceso educativo de una manera sencilla; la mujer aprende los conocimientos básicos de higiene y los aplica directamente sobre sus hijos, al tiempo que se los transmite, cumpliendo la doble función de educada y educadora. Las Escuelas del Hogar no debían ser ajenas a la enseñanza de la higiene, pues además de tener en sí mismas el carácter de cultura general, eran un excelente auxiliar de las clases de cocina, al enseñar «a la mujer a preparar una alimentación sencilla y sabrosa, e instruirla acerca de muchos particulares, por lo que al empleo de los alimentos se refiere» (28). La educación higiénica de la mujer adquiere tintes de talismán frente a los problemas sociales, pues si bien no hay la posibilidad de «proporcionar a todos los pobres palacios donde vivir, enseñemos a la mujer... los milagros que puede hacer una buena higiene» (29). Una vez más se lanza la idea de que la educación basta para mejorar la vida del obrero sin necesidad de transformar el orden social imperante.

\section{El problema de la mujer alcohólica}

Pese a esta descripción de la mujer ideal y de la noble misión de educadora que le corresponde, existe la preocupación por la mujer alcohólica. Si bien se parte de la base de que ésta tiene una tendencia hacia la abstinencia que «atenúa la acción degradante del alcoholismo y permite que subsistan todavía las poblaciones viciadas por él» (30), se constata un aumento de mujeres bebedoras (31) que inquieta a los médicos porque

"tanto y de tal modo se degrada la mujer cuando se entrega a la bebida, y a tal exceso llegan los males que se acarrea y acarrea a los suyos, que no es humanamente posible que virtud ninguna resplandezca sobre su frente ni que luzca un día de sol para su causa. Reparese, sino, en lo que hemos visto quedaba convertido el hombre alcohólico, y reparese luego en la misión social que a la mujer le corresponde. ¿ Es posible que desempeñe éstas, la que se halle en las condi- 
ciones de aquél, la que en lo físico esté sujeta a continuos vértigos, insomnios, pesadillas, anestesias, etc., y en lo moral a degeneraciones, perversiones, faltas de memorias, alucinaciones y delirios?» (32).

Junto al problema de su incapacidad para educar a sus hijos y dar ejemplo de moralidad, también se plantea la cuestión del agravamiento de la degeneración de la raza, ya que «durante la evolución intrauterina el feto sufre todas las consecuencias de los excesos alcohólicos de la mujer que lo lleva» (33). Existe por tanto una diferencia de juicio entre el alcoholismo masculino y el femenino, que arranca de la distinta concepción de los roles sociales de cada sexo, lo que en el caso femenino provoca una postura más moralista y peyorativa.

El análisis de las causas del aumento del alcoholismo femenino, curiosamente, tiene una explicación fundamentalmente basada en el medio social en que se desenvuelve la mujer. Se suelen atribuir dos causas medio-ambientales. La primera es el mal ejemplo de un esposo alcohólico que incita a la mujer a sumarse al vicio. La segunda, que a nuestro juicio constituye la más interesante por la trascendencia social que posee, está ligada a un análisis más sociológico, pues atribuye el problema a las nuevas condiciones socio-económicas que provocan que la mujer

"cada vez menos sujeta en el hogar, por efecto de nuestras nuevas costumbres y de nuestros novísimos hábitos, se lanza fuera de él llamada por ocupaciones nacidas de nuevas condiciones o de nuevas necesidades sociales; se exterioriza cada vez más, si así puede decirse, y acechada por las mismas ocasiones y sugestionada por los mismos medios que arrastran al hombre, acaba por cometer los mismos abusos" (34).

El trabajo de la mujer es uno de los problemas fundamentales que se planteó a la medicina a la hora de abordar el entorno familiar. La Medicina Social contribuyó así con la autoridad que le daba su halo científico a un debate más general que existía al respecto en determinados círculos académicos, partidos políticos y organizaciones sindicales y en el seno de algunas organizaciones de carácter femenino (35). En los textos investigados para este trabajo, se parte de la idea de la constitución especial del organismo femenino «tan delicado y tan complejo" (36) sobre el que el trabajo ejerce una influencia perniciosa; al ser 


\begin{abstract}
«causa determinante de alteraciones orgánicas actúa sobre la mujer en su período de formación y en su estado de desarrollo completo y además, y muy especialmente, en ciertos momentos de su vida en los que su organismo, además de llenar sus funciones ordinarias, desempeña la eventual e importantísima de la reproducción» (37).
\end{abstract}

Lógicamente esta acción sobre la salud femenina, no podía dejar de trascender para la mentalidad médica de la época «sobre la descendencia que de ella procede», contribuyendo a la degeneración de la raza (38). Dos posturas se pueden definir del análisis de estos textos respecto a la conveniencia o no del trabajo femenino. La primera considera en sí misma dañina la actividad laboral de la mujer, mientras que la segunda atribuye a las condiciones en que se desarrolla el trabajo los efectos nocivos sobre la salud (39). Sin embargo, los autores lejos de proponer la reclusión de la mujer en el hogar, son conscientes de que el salario de una familia obrera se puede ver mermado sin la paga femenina, y por tanto aumentar la miseria obrera y con ella los factores de desestabilización social, además de no ignorar el imprescindible papel de la mujer en el proceso productivo. La cuestión que se les planteaba a los propagandistas de la Medicina Social era la de cómo armonizar la misión de la mujer en el hogar antes descrita con la realidad del mercado de trabajo, especialmente en los estratos obreros. La solución hacia la que se dirige la Medicina Social, entroncada en la corriente general de reformismo social de la Restauración, es la puesta en marcha de una legislación dirigida a proteger el trabajo de la mujer, encaminándolo hacia actividades en las cuales no sufra el desgaste al que está sometida, estableciendo una regulación de los horarios, prohibiendo por ejemplo el trabajo nocturno, y «asegurar el feliz éxito de las funciones de reproducción, no sólo en interés de la madre, sino del producto de la concepción (descanso antes y después del parto y horas para la lactancia de los hijos)» (40).

\title{
Conclusión
}

En definitiva la Medicina Social trata el tema de la mujer desde la perspectiva de su doble condición de madre y esposa. Dentro de esta tendencia general de la sociedad española de la Restauración los médicos tejen un discurso, teñido de cientifismo, dirigido a mantener esa concepción, instrumentalizando a la mujer para reforzar su papel en este sentido y establecer de paso un control sobre el entorno familiar, 
en nombre de los principios higiénicos. Desde este punto de vista la mujer debe ser educada, en tanto y cuanto su educación sirva para establecer los pilares de un hogar ideal. El caso del alcoholismo, sin ser el único, es un ejemplo evidente de este utilitarismo científico enormemente cargado de moralismo e intenciones políticas, cuyo fin último es el control de las clases sociales consideradas peligrosas por la bienpensante burguesía decimonónica.

\section{NOTAS}

(1) En 1883 se creó la Comisión de Reformas Sociales, con la intención de estudiar y solucionar diferentes aspectos de la cuestión social. Con ella se inició en España la intervención del Estado en materia de política social, aunque de manera tímida y rodeada de la desconfianza general. En 1903 se creó el Instituto de Reformas Sociales y en 1908 se fundó el Instituto Nacional de Previsión. En 1920, como jalón final, el Estado constituyó el Ministerio de Trabajo. La institucionalización del reformismo social en España fue producto de un lento proceso e intenso debate en el seno de las élites políticas e intelectuales españolas, influido por las diferentes políticas reformistas que se desarrollaron en Europa y por las diferentes corrientes socio-políticas del momento. Para un buen resumen de los debates que se establecieron en España en los últimos años del siglo XIX y primeros del xx sobre la cuestión social, véase MONTERo GarCía, F. (1988): Los seguros sociales en la España del siglo XX. Orígenes y antecedentes de la previsión social, Madrid, También es de interés la obra CALLE, María Dolores de la (1989): La Comisión de Reformas Sociales 1883-1903. Politica social y conflicto de intereses en la España de la Restauración. Madrid.

(2) Algunos autores hacen referencia a la borrachera de la burguesía, a la que juzgan como igual de perniciosa para la sociedad que la del obrero. Sin embargo, las medidas especiales que se proponen para paliar el mal van siempre dirigidas a la represión de las clases más desfavorecidas. Entre los autores que mencionan el problema de la embriaguez de la burguesía están SANGRo y ROS DE OLANO, P. (1904): Estudio sobre el alcoholismo y males que ocasiona al individuo, a la familia y a la sociedad. Madrid, que en la pág. 33 afirma que "la desmoralización de la familia no es exclusivamente patrimonio diabólico del alcoholismo de los de abajo. Las clases elevadas sufren también su acicate». Asimismo Ferrer y Garcia-Tejero, E. (1910): El alcoholismo y la criminalidad. La descendencia de los alcohólicos. Consejos higiénicos, Madrid, en cuya p. 29 se defiende la necesidad de castigar por igual al pobre y al rico borracho, aunque las motivaciones para el castigo de los primeros están basados en el paternalismo, pues las clases directoras deben dar buen ejemplo a los productores.

(3) Sobre el degeneracionismo en la psiquiatría francesa, véase la obra de HUERTAS, R. (1987), Locura y degeneración, Madrid. En España es interesante la constatación de que la mayoría de las estadísticas utilizadas para demostrar las relaciones entre locura, criminalidad y alcoholismo son francesas. Sólo he encontrado un trabajo referente al alcoholismo en España que elabore estadísticas españolas. Me refiero al estudio del Teniente Fiscal de la Audiencia de Oviedo, Gimeno de AzCarate, M. (1900): La criminalidad en Asturias. Estadística (1883-1897), Oviedo, en el que se intenta demostrar la relación directa entre la excesiva ingestión de bebidas alcohólicas con el aumento de la crimina- 
lidad en la región. Ni que decir tiene que este estudio es uno de los más citados por el resto de autores españoles, cuando necesitan cifras que demuestren sus afirmaciones. Asimismo se utilizan los autores franceses para las citas de autoridad (y no siempre se citan sino que, se asume el pensamiento de estos como propio). Morel, Magnan y Legrain son los más utilizados.

(4) Muñoz Ruiz de Pasanis, A. (1906): El alcoholismo. Su influencia en la degeneración de la raza latina, Madrid, p. 80.

(5) Ferrer y Garcia-Tejero, E. (1910): El alcoholismo y la criminalidad. La descendencia de los alcohólicos. Consejos higiénicos. Madrid, p. 20.

(6) Tomado de Legrain, P. M. (1891): Dégénerescence sociale et alcoolisme, Paris.

(7) Ubeda y CoRreal, J. (1901): El alcoholismo: sus efectos en el individuo y en su descendencia: su influencia desmoralizadora en la sociedad y en la familia. Consejos y medios para combatirlo y desterrarlo. Madrid, p. 100.

(8) Entre los defensores de que el medio social es la causa que conduce al alcoholismo se encuentra SANGRO y Ros DE OLANO (1904): p. 17, que considera las condiciones de vida del proletariado como la causa principal de su tendencia al alcoholismo, aunque en la p. 39 responsabiliza al obrero de su propio pauperismo al invertir elevadas sumas en alcohol y mermar así sus ingresos. También en la obra de Malo EcIJA, B. (1900): Alcohol y alcoholismo ante la higiene. Ensayo de estudio médico social, Madrid, se hace hincapié en las condiciones sociales como un factor a tener en cuenta. Por el contrario Muñoz Ruiz de Pasanis (1906): p. 40 y Ubeda de Correal (1900): p. 150, resaltan la responsabilidad del alcoholismo en la miseria del proletariado y la intemperancia de este.

(9) Ubeda y CoRreal (1901): p. 150-151.

(10) LOPEZ GOMEZ, Q. (1910): El alcoholismo. Sus efectos y medios para evitarlo.

(11) LOPEZ GOMEZ (1910): p. 22.

(12) UBEDA y CORREAL (1901): p. 173.

(13) Ubeda y CoRreal (1901): p. 151 y 173.

(14) Alvarez-Uría, F. (1983): Miserables y locos. Medicina mental y orden social en la España del siglo XIX, Barcelona, p. 324

(15) Para una visión global del pensamiento sobre la misión de la mujer en la sociedad de la Restauración y de las discusiones mantenidas al respecto, véase la obra de SCANLON, G. M. (1986): La polémica feminista en la España contemporánea 1864-1976, Madrid. También NASH, M. (1977): «La problemática de la mujer y el movimiento obrero en España» en Teoría y práctica del movimiento obrero en España (1900-1936), 243-279.

(16) Pérez de Muñoz Iriarte, E. (1923): Escuelas del Hogar. Cuál debe ser su organización y qué materias de Enseñanza deben comprender para la educación útil de jóvenes de clases modestas, Madrid, p. 8.n Las Escuelas del Hogar estaban reguladas por el R. D. del 7 de diciembre de 1911, el Reglamento del 3 de junio de 1913 y el R. D. del 15 de junio de 1925.

(17) Pérez de Muñoz Iriarte (1923): p. 10.

(18) Pérez de Muñoz Iriarte (1923): p. 10.

(19) Pérez de Muñoz Iriarte (1923): p. 10.

(20) Ubeda de Correal (1901): p. 156.

(21) Ubeda DE CoRreal (1901): p. 174.

(22) Pérez de Muñoz Iriarte (1923): p. 9.

(23) LOPEZ GOMEZ (1910): p. 27.

(24) LOPEZ GOMEZ (1910): p. 28.

(25) LOPEZ GOMEZ (1910): p. 28.

(26) LOPEZ GOMEZ (1910): p. 29. 
(27) BuisÁn Pellicer, E. (1912): Educación higiénica de la mujer y su influencia en el desarrollo físico y moral de la de los hijos, Madrid, p. 10.

(28) BUisán Pellicer (1912): p. 41.

(29) Buisán Pellicer (1912): p. 41

(30) Ferrer y Garcia-Tejero (1910): p. 26

(31) Ubeda y Correal (1901): utiliza los datos de Garnier y Magnan para Francia con el fin de demostrar que el alcoholismo femenino aumenta, pp. 75 y 76 .

(32) LOPEZ GÓMEZ (1910): p. 21.

(33) Villegas MonTesinos, M. (1911): El peligro alcohólico, Córdoba, p. 54.

(34) UBEDA Y CORREAL (1901): p. 75

(35) SCANLON (1986): pp. 58-121.

(36) UBEDA ARCE, J. (1913): El trabajo de la mujer en la industria: condiciones en que se efectúa y sus consecuencias en el porvenir de la raza. Medidas de protección necesarias.

(37) UBEDA ARCE (1913): p. 6.

(38) Ubeda AARCE (1913): p. 6

(39) González Castro indica al respecto que «en España por grande que sea el esfuerzo en el trabajo, no puede una mujer subvenir con el producto de aquél, a las más perentorias necesidades de su vida. Y cuando lo consiga, merced a un esfuerzo inhumano, no podrá sufrirlo por mucho tiempo, pues vendrá el agotamiento físico y moral, que dará en tierra con el más fuerte organismo femenino». GonZAlez CASTRO, J. (1915): Medio de hacer más productivo el trabajo de la mujer, para que, sin detrimento de su salud, pueda atender a las necesidades primordiales de su existencia, Madrid, p. 7.

(40) UBEDA ARCE (1913): p. 35. 